\title{
I AM WHO I AM
}

\section{Pacific tertiary students and the centrality of ethnic identity for successful outcomes}

\author{
Melani Anae* \\ Ingrid Peterson ${ }^{\dagger}$
}

Pikipiki hama kae vaevae manava

\begin{abstract}
This article is about a university course which decolonises the classroom by making culture count. It examines how the ethnic identity journeys of 13 Pacific students in a third-year course in Pacific Studies run by the University of Auckland define and derive meaning for a more secure ethnic identity as a strategy for success across teaching/learning and life courses. It also shows that in the context of a New Zealand monocultural education for Pacific students across all sectors, while good courses and teachers get the job done, great courses and teachers have the potential to liberate and heal. The main aim of the research this article is based on was to investigate how the influential factor of a secure ethnic identity contributes to Pacific students succeeding well in their studies. Developing a secure ethnic identity is defined here as the transition from a confused ethnic identity caused by obstacles and hardships experienced by challenges to one's ethnic self-identity to a secure ethnic identity where resolution of a stable ethnic identity is reached over time, despite these challenges (Anae, 1998; Manuela \& Anae, 2017). Students' pre-course ethnic identity understandings were articulated in their life story interviews (Olsen \& Shopes, 1991) at the beginning of the course, and their secure ethnic identity transitions were gleaned from the identity journey essays they wrote mid-course, as well as focus group discussions held at the end of the course. This article also seeks to ascertain the nature of any trends in teaching and learning (curricula, ethnic identity issues) which support or constrain a secure ethnic identity. Finally, it calls for strategies, changes to environments, teaching/learning communities, courses and curricula that allow students to think, write about and act on their ethnic identities to support Pacific success in their studies, within their families, and in their wider communities.
\end{abstract}

\section{Keywords}

ethnic identity journey, ethnic enhancements, secure identity, student success, inter- and intra-ethnicity

* Senior Lecturer, Pacific Studies, Te Wānanga o Waipapa, University of Auckland, Auckland, New Zealand. Email: m.anae@auckland.ac.nz

$\dagger$ Research Assistant, Centre for Learning and Research in Higher Education, University of Auckland, Auckland, New Zealand. 


\section{Introduction}

This article focuses on Pacific 300: NZ-Born Pacific Identities, a third-year course which examines the ethnic identity construct and its relationship with well-being taught over one semester at the University of Auckland. The course provides a space where Pacific students' (and students of other ethnicities') notions of self-defined ethnic identity are examined, explored and experientially written about using European and Pacific theories of ethnicity and students' own experiences. This article analyses this course through participants' lenses of success and a transition to a secure ethnic identity, thus providing optimal and healing outputs from the course learnings. Rather than a cultural enhancement course, this process positions the course as an ethnic enhancement course (Manuela \& Anae, 2017).

\section{Methodology}

The qualitative research project on which this article is based tracked students' experiences of the course. It consisted of thematic analysis of focused life story interviews (see Olsen \& Shopes, 1991) during the first week of Pacific 300 classes, which explored understandings of success, ethnic and cultural experiences, family life and schooling. These were followed by thematic analyses of students' ethnic identity journey essays (mid-course) and focus group interviews which were held at the end of the course.

The research project took place from 16 July to 19 October 2018. All students enrolled in Pacific 300 were invited to take part in the research. Participants consented to the interviews and their identity journey essays being accessible to the researchers. All participant names and data were kept confidential to the researchers. Students were also invited to complete a demographic questionnaire, the results of which are presented graphically in Appendix 1. None of the individual/focus group interviews took place during class times. Out of a class of 34, 13 students participated in the project. The focused life story interviews at the beginning of the course took between 1 and 1.5 hours, and were held on campus at a date, time and place which suited the participants. The interviews centred on students' experiences of their ethnic identities themed across schooling during primary, secondary and tertiary stages. Participants were asked what it was like to grow up "Pacific" in Aotearoa New Zealand. The life story methodology was enhanced by the teu le va methodology (Anae, 2016), whereby the interviewer/interviewee relationship was a respectful one, cognisant of the sacred and secular spaces of relationships. The focus group interviews were held during the last week of lectures and focused on thematic areas from the life story interviews that were not covered in the identity journey essays. Out of the 13 participants (two were male and 11 female) who took part in the project, nine participated in the focus groups. Two focus group interviews were held.

\section{Research findings}

This section contains the description of the course, the thematic analyses of the life story interviews at the beginning of the course and of the ethnic identity journey essays, and the analysis of the focus group interviews held at the end of the course. Overall, the research findings describe the transitioning for some of the students from the positionality of ethnic identity confusiondescribed as "challenges" to their own perceived ethnic identities-to a secure ethnic identity position where learnings from the course have provided "coping" and "empowering" strategies.

\section{The course}

Pacific 300: NZ-Born Pacific Identities explores the complex issues of growing up as a member of a minority ethnic group or bi/multicultural person and how these dual or multiple identities affected and/or interacted with an individual's behaviours, priorities, social relationships and concept of self. The concept of intra-ethnic identity was also explored, allowing the researcher to ascertain ethnic issues within each participant's own Pacific ethnic group. To achieve a broad understanding of ethnic issues, part of the course used a cross-cultural perspective in which materials about minority ethnic groups and inter-ethnic relations in New Zealand were examined. Case studies from other countries provided comparative global perspectives. Special emphasis was given to class discussions, creative writing, and the exchange of viewpoints.

The four coursework components consisted of a literature review, a book/film/music album review, an ethnic identity journey essay and an oral presentation. The literature review surveyed European and Pacific theories of ethnicity. The book/film/ music album review was based on course materials that analysed the local/global ethnic identity journey of a published Indigenous novelist, poet, rapper, musician or playwright from an ethnic group other than the students'. In the middle of the course, students wrote an essay describing their own ethnic identity journey. The students' oral seminars were presented individually, in pairs, 
or as a group presentation. These presentations, which were based on their identity journey essays, took the form of a summary of their essay, a song, a poem, a performance, role-play, a rap, a painting, weaving or other creative piece, or a short video.

\section{Life stories before the course}

Life story interviews centred on growing up as a "Pacific" person in New Zealand. Emanating from the students' experiences were themes of home (relationships with parents and families, support systems, culture of the home vs palagi spaces, interpretations of success); schooling (intersectoral experiences and influence of teachers and schooling, career aspects); stress points (challenges from both palagi and other Pacific Islanders about their self-perceived ethnic identities, identity confusion, trying to find the balance between home/school; being a Pacific "academic" person, racist experiences); and coping mechanisms (support from family and church, achieving goals, helping families financially, serving and respecting families.

The 13 participants in the life story interviews were made up of 11 females and two males, and their ethnicities consisted of eight Samoans (including one self-ascribed Afakasi-Samoan), three Tongans and two Cook Islanders (see Appendix 1 for more detail). In presenting quotes from participants, and across the life stories/identity journeys/focus group, the following coding system is used: Participant number/Gender/Ethnicity. For example, P[No.], $\mathrm{M}$ [ale], S[amoan]) This coding system is used to maintain the ethical consideration of keeping participants' names confidential. It is interesting to note that across the three ethnicities birthplace seemed irrelevant to self-ascribed ethnicities. For example, while some Samoans were born in New Zealand, they self-ascribed as "Samoan", others as New Zealand-born, and so on.

\section{Home}

When speaking about home, participants stressed the centrality of home and family and the tremendous support they received from their grandparents, mothers and siblings. Most started with the stories of how either one or both parents came to New Zealand as Pacific migrants, and the difficulties they faced as they settled in a new country-problems with the language, getting a "good education" and the sacrifices made to give their children a "better life".

My dad didn't even finish year 10 and it was that sacrifice that I know that enabled me to set foot on campus, and when I don't want to get up like my biggest challenge is getting up in the morning because I . . . it's cold and I have to catch an early bus to uni just to get here on time. I think about how they surely didn't want to get up in the morning to like go work or umm, you know, make ends meet but they got up anyway for me and I just need to get up today to ensure that it's going to work out. ... I always refer to that when you know the going gets tough. (P1FS)

Many speak about the need to communicate and explain to their parents how the tertiary institution works, the rigour of university systems, and the economics of "passing well" because of scholarships and through course grades assessments.

I literally explain to my parents the downfall of what would happen, how hard it is to get to this university, how easy it is to actually like get dropped if you don't do good . . . the GPA [grade point average] systems, the grades you should get if you're on scholarships, the grades that you don't want to get ... (P2MS)

Many participants spoke about how important it was for them to succeed in life. There were differing definitions of success. Many spoke of the competitiveness required of them to get top marks. Overwhelmingly participants spoke about the need to win certificates and high educational achievements in order to "please" parents and to make them happy.

Yup-success was always winning, getting certificates, especially ... rewards from teachers in primary, and then in high school . . . always getting that one spot on the top. That was success until I came to uni. There was no such thing as ranking and each year they're not going to say, "Oh you've done so well, here's something to reward you with" ... (P4FT)

I completely denied my identity as a Tongan in order to assimilate to the culture that is believed to enhance opportunities and success. This was the mindset and attitude that I continued to carry all throughout primary, intermediate and high school education. (P12FT)

Other participants saw success in terms of education as a means of "getting a good job", to become rich and to support their parents and families, and were cognisant of the additional dimension of cultural roles and obligations. 
I know as a 10 -year-old I wanted to be rich. I actually wanted to be really rich ... [laughs] but through high school success was actually coming to uni and now while I'm at uni it's actually getting a degree and actually getting a good job so I can provide for my family. I think that's success and making my parents happy. That's success for me. (P7FS)

\section{Schooling}

While participants' primary school experiences were mostly fondly remembered as "enjoyable" and "fun", secondary school experiences were very different. Some secondary schools had "Pacific spaces", which made some participants feel comfortable, accepted and celebrated. It also gave them a strong sense that their Pacific ethnic identities were solid. For some, this grounding disappeared when they moved on to tertiary institutions where they were definitely the minority, and this made them feel alienated and unwelcome.

I went to AGGS [Auckland Girls' Grammar School]. I feel like I was comfortable in my skin and there was no question of who I was because my school was very diverse . . . like we have PI's [Pacific Islanders] . . . at our school and they really talk about strong tamaitai [young women]. . . . At uni ... I feel like when I go to my science papers and then it's predominantly palagi and then there's me sitting in the corner and I feel like I can't breathe until I come here . . . I feel like I can't breathe or relax until I come to Arts, you know, like my safe space ... (P1FA-S)

The power and influence of teachers at secondary level and beyond who can "make you" or "break you" was glaringly apparent in many of the narratives, especially for P4FT: “. . . because sometimes I just get scared of asking them [teachers]. Because of the whole mindset that she's too stupid to ask in class, so why would you need help afterwards?" She continued:

When [a male lecturer] gave the lectures, we just felt comfortable with the way he lectured and when we wanted to go ask for more help he'd just willingly help. But I think it just has to do with the way they sort of answer the questions or put themselves up there. Because there are some lecturers who when you go ask them for help, they're quite stand-offish. ... And then that's when you just, "Yeah I'm not going to come and ask you a question again."

$\cdots$
I loved Mozart. . . . I could play sports, but it wasn't my first choice. . . . But every time I got my schedule back, I'd be put into PE. I guess that's where I encountered my first white teacher who stood up for me because he came in and he was like "Do you want to do classical music?" and I said: "Yeah", and then he said: "Do you know how to read music?" and I said: "Yeah, I know how to read music", and then he was like "Let her in."

\section{Ethnic identity stress points}

Most of the stress points in the life story narratives concerned ethnic identity confusion and the cultural tensions between roles and expectations around being both a Pacific person and a university student, and how "switching between [the] two" impacts on family members.

Like I have to switch my mind, and my mind becomes intellectual and academic. ... I didn't realise the way I was talking until my brother was like "Why do you always use big words?" ... So I feel like that's an ongoing journey for me as I'm always switching between two.

\section{$\cdots$}

Not being able to speak mother tongue is another ethnic identity stress point, one which is compounded when one's parents are NZ-born or raised. (P5FS)

I think yeah-you need a strong hold of it like you know the language even though you don't speak it but at least understand it, then you're fine. I guess with them [parents] it's just they grew up and so they came at a really young age and so they grew up with the whole palagi mentality, I guess, and my parents didn't put too much emphasis on the language or like speaking at home. Even at home we don't speak Tongan. We only speak English, and it's fine with them, so I guess that's why they're just like "Oh they're not Tongan." Especially when they go out with their friends and stuff because of all the stereotypes with all the Islanders, they don't say it out loud. (P4FT)

Perhaps the strongest and most common stress point amongst the participants was their overt experiences of racism and sexism, which, prior to the course, the participants had no intellectual way of dealing with. The anger and bitterness they experienced, for many on a daily basis, remained in their psyche, in deep spaces of sorrow, hurt and pain. 
Because the [workplace] ... is predominantly European it is always a struggle for me because not only am I a Pacific Islander but I'm also a woman, and so there's the struggle of breaking the stigmas that already exist within the film industry ... which is Pacific Islanders are usually in front of the cameras and they act, and if they're behind then they're usually the catering unit. Like I got asked that so many times on that first film shoot. When I walked on, they were like: "Oh where is the unit?", which is the film terminology for catering, and they were like "Is the unit here?", and I was like "I don't know". He was like "Oh, you don't know ... Oh, what are you doing here?” And I'm like "I'm a producer, I'm the producer for this film set", and then they just like take a second and then I think they realise almost their racism they've just done and then they're like "Oh, it's so great to have you", and I'm kind of like "Yeah . . . you just kind of just snapped yourself out." (P5FS)

Some participants also recalled school place racism and the anger at being racially profiled with Pacific stereotypes, for example, as a thief:

... then I got called up at lunch and I walked up to the office and there were the other two Islanders in the school, and it was us three. I mean I still remember her name now.... She asked me to come into the class and then she said to me: "You won't be in trouble, but you just need to tell me the truth. Why are you taking lunch out of these kids' bags?" And I thought, first of all, you didn't even ask: "Are you taking lunch out of these bags?" You just completely just said: "Why are you taking ...”, and I remember just being gobsmacked, and I remember that was my first real ... I guess that was my first interaction with racism. (P5FS)

The impact of racist attacks, taunts and stereotyping was described by participants as making them "out of balance", as "affecting schoolwork" and making them "feel unwell". Some participants feel confused about the extent of this impact when they are otherwise a "good" and obedient son/daughter who keeps the "links" with family members and who are "successful" in their studies.

Yeah, I think mental health is so important . . . that would be a big one for me. Because I feel like when I'm not in balance, like just how much that kind of mucks me up. So I feel like success is being like I'm okay, I'm on top of my work, I've been going to church, praying or journaling-something to do with my mental health or spirituality. You know
I've been in contact with my mum and my brother this week so I'm feeling-like those relationships of maintaining, so yeah and obviously getting good grades. It's not so much I think getting good grades, it's more that doing the best that I can be doing if that makes sense. That I know, okay, I didn't say get an "A", but I know that I gave that my all. Like what more could you ask for? (P3FA-S)

\section{Coping mechanisms}

Participants' narratives prior to their course learnings described a variety of coping mechanisms for the racism and ethnic identity confusions that they experienced. Most participants talked about success being the strongest coping mechanism. With success they will be able to be good "Pacific children" who support and serve their parents and extensive Pacific families in New Zealand and abroad.

Success to me means achieving my goals, and when I do achieve them, I'm completing the tasks that need to be achieved at the best of my ability, so not half-do anything and ensuring that when I achieve my goals it means that umm there is stability in my home. Like I'm doing something, my goals mean something ... [which] also means that I can help my family, help my parents and those abroad. (P1FS)

The same participant spoke about the frustration they felt about not being literate in their mother tongue. Most would only seek help from a counsellor as a last resort; others sought other coping mechanisms.

I write in my book and then I go to eat, or I go to Albert Park and read, and you know to realign my focus. When things get really tough, I'll go to . . . if it gets really tough, then I'll go to . . . the counsellor or I'll seek official help, but I just read my book. Yeah, I think sometimes there's this language barrier or embarrassment or shame ... (P1FS)

One participant, who lived through the Christchurch earthquakes, had struggled with her mental health and coped by just "off-loading" to a counsellor or her mother. Her narrative reinforces that it is "okay" to ask for help in dire circumstances.

I'm definitely someone who is proactive, and I learnt quite early on just how important it is to ask for help and, yeah, after the earthquakes in Christchurch it was just like a crazy time, and I 
got-well I wouldn't say I got depressed, but my mental health definitely did take a hit. I just remember the burden just getting lifted off my shoulders once I went to see a guidance counsellor, and then from that talking to my mum and so that just taught me just like ask for help, put away your ego and your pride. It's okay not to . . . like, don't see it as a weakness. (P3FA-S)

\section{Identity journey essays}

The identity journey essays were written purely from personal experiences and involved intellectual-engagement issues that are often confronting to students on a personal and collective level. Many participants said that writing their essay was an empowering experience because it allowed them to negotiate their way through both positive and negative reflections of their own self-identities and the challenges to them. This is not to say that their personal issues were resolved. Rather, it gave students the opportunity to use and appreciate acquired inter- and intra-ethnic skills to try and negotiate a way through what were overwhelming events for many. It also highlighted the privilege of having a healing and liberating education that allows them to think their way through issues, rather than relying solely on others' representations of who they are. Below are excerpts from participants' identity journey essays.

I feel that my ethnic identity has improved. . . . I find myself secure in who I am and what I want to become in the future. I used to think of my culture as dull, useless and a waste of time. However, . . . I now realise the value in cultural practices and traditions, I am New Zealand-born, I am Tongan. (P10FT)

Joining [this course], solidified my identity. It was a course which introduced a space that was unique and part of who I am. ... This course helped me to make sense of who I am, where I have come from. ... It has allowed me to go home and have conversations with my parents about ethnic identity. I always wondered "what if . . I did not take the course?" Will I still be courageous towards my Pacific ethnicity or not? I am grateful to learn about amazing Pacific scholars which contribute and help shape a persistent Pacific worldview that many take for granted. ... As the year progresses, I am still transforming and am still learning who I am. (P6FC)

Three years have passed since I shaved my head. My hair is now just past my shoulders. I've bleached it twice and dyed it four times. Today, I've come to appreciate my hair. I've lost my tight curls for good now. But the wavy curls which remain I absolutely adore, even after all that bleaching. I see my identity journey as an extension of my journey with my hair. From losing my tight curls and praying for white skin, shaving my hair and re-evaluating my identity, to growing my hair from the beginning and finding myself through siva [Samoan traditional dance]. My hair is still growing and inevitably so am I and my journey in understanding myself as a Samoan. Thank you. (P5FS)

In summary, I can say that through [this course], I have come to think about my identity critically. The labelling convention-like my name makes me appreciate it more. My appearance, I am not too fussed about because it is what is on the inside that matters and not the outside. The Tongan concepts that my dad has tried to teach me, and my siblings play a major role in my life. I am always trying (emphasis on trying) to keep the Tongan values and practise being Tongan. And I cannot say anything about possibly marrying. I always tell people that I love kids, so I think I'd just end up being a single mother with 10 adopted kids. We'll see what the future holds. (P12FT)

All in all, the core values normalised in Samoa that differentiates from other cultures portrays the significance of one's identity, the unique pride one has over the other and the sentiment of belonging to another culture that isn't necessarily salient or first-placed in the diaspora. To have a sudden realisation of the little things that contribute to the strengthening of my identity journey is manifested through who I identify as, the practices of my culture and traditions, my ekalesia [church], and lastly language. (P2MS)

It is scary to think of the dangers of losing our identity, and how it will eventually cost us our mental health. (P1FS)

This course completely flipped my point of view, it burned the assumption that there is nothing to learn about the Pacific. . . simply because we allow it to happen. ... However, the most significant impact of this exposure, was the ignition of pride through support and encouragement. I was able to rediscover my purpose as a student but also as a young first-generation migrant female. (P12FT)

Analysis of the identity journeys essays suggests that Pacific students' initial perceptions of success 
such as "achieving goals" and helping families financially (through a good education and securing employment) at the beginning of the course had developed into notions of tautua-serving and respecting parents and families - and the feeling of satisfaction from what one has achieved by the middle of the course. The focus on ethnic identity helped them to demystify accusations of being "plastic" and to challenge the racial profiling they experienced. It has also provided a space for them to find balance and a holistic sense of who they are. Some participants had realised that these challenges, if not reconciled, can lead to unwellness and mental health issues.

\section{Focus groups}

The focus group interviews revealed that experiencing the course and understanding the theory and practice of the ethnic identity journey had extended participants' perceptions of success in their life story interviews at the beginning of the course. Two very vocal focus group participants in particular were adamant that they had been empowered by life-changing learnings from the course. For P3FA-S, her ethnic self-ascription had changed from Afakasi-Samoan to Samoan, and she had a newfound pride and confidence in her "secure" identity. She shared the following during the focus group interview:

... such a nice feeling to be at uni and know the grounding in your ethnicity and your ethnic experiences. They're all important things in shaping you and YEAH, THEY MATTER! [expressed with appreciation and happiness].

\section{$\cdots$}

After [this course] I feel more grounded and more secure in my identity. I feel more balanced. Not feeling balanced or secure in my ethnic identity would lead to mental health issues but because of this paper, I've been able to critically analyse my journey and myself and I feel good ... like, in a sweet spot-it's really grounded me.

\section{$\ldots$}

Just someone being interested in who I really am. ... The feeling that you don't have to leave part of yourself at the door when you come into class.

$\ldots$

I think I could get by life, uni, etc., without acknowledging my ethnic identity . . . but I wouldn't be happy, or I wouldn't be honouring myself. Like, you know how I talked about being in balance I always use this and that would take me off balance and so then I could probably go through uni and life but not very well.

A pivotal moment for P3FA-S was when she was recently challenged about her Samoanness by another Samoan who called her a "plastic Samoan":

Previously, these statements would have made me very upset and uncomfortable and I would've internalised them. Now I don't feel as affected by them because I don't crave validation in my identity as a tamaitai Samoa. I feel a little annoyed at this student's ignorance, but I don't feel upset nor does it make me question my identity. ... Putting me down enables them to feel more superior in their knowledge and identity. I didn't realise how far I had come in my ethnic identity journey until I was confronted by this student's comments. It was such a strange but a nice feeling to be so secure that I was not affected by her words.

For others, early understandings of meanings of success such as "getting money to help parents" had been re-evaluated to "not just the big things . . . like material things, but maximising knowledge and skills and abilities at every level. Helping my parents out financially are just bonuses". "Giving back" was another theme in focus group discussions, especially in relation to parents' migration stories. Another life-changing experience occurred for P6FC. What changed for her was that her ethnic identity as Tongan Cook Island counted. She had come to realise that in multi-ethnic and diverse contexts knowing one's ethnic identity and where one comes from provides more understanding about diversity, different cultures and different lifeways.

I didn't consider my identity or culture as part of my education, so coming to university, everything has fully changed. Now I feel a lot closer to my identity than I was back then. In high school or in intermediate or primary I felt like I didn't really care much about who I was. For myself I felt like as long as I knew I was Tongan Cook Island that was more than enough. But with university ... everyone tends to know where they come from and all this and so I felt like I needed to also know more ... I feel like if I'm able to understand more who I am or know who I am, it will help me with other 
career pathways. Like say for example if I were to go and do case managing there will be families I will come across who have issues and maybe if I didn't have the view that I have now I'd be biased in some kind of way. Whereas knowing all this knowledge and able to be accepting and understand other circumstances or situations or like people's problems . . . so more of an understanding point of view rather than being like one-viewed. (P6FC)

This course empowered these two students referred to above in life-changing ways. Experiential and existential exercises that are engaging, inclusive and challenging and facilitate serious conversations are incorporated in Pacific 300. Feedback from students who took part in the study reveals that they felt the course work, although difficult, was more rewarding than that of other papers. They found it empowering because it forced them to understand and apply theory to practice; it enabled them to intellectualise and evaluate their own ethnic identities in a way that provided them with a newfound confidence, self-reflexivity, a new self-respect and a secure identity. Based on both European and Pacific ethnicity theories and their own personal identity journeys, they were able to demystify "racism", "difference" and "self-identity". As a consequence, they were able to analyse and articulate theories of ethnicity with their own identity experiences, thereby rationalising coping mechanisms along the way.

Pacific 300 provides students with space to disturb existing experiences, perceptions and thinking about who and why they are; why the correct pronunciation of their names correctly is important to them; why the negative stereotypes of South Auckland are not who they are; why they no longer regard themselves as plastic Samoans/Tongans or half-castes. This allows them to understand and engage with themselves, their peers, lecturers, their academic work, their families and their ethnic communities, as well as other ethnic groups and the wider New Zealand communities, and to connect with "difference" in positive ways to optimise their ethnic identities for successful outcomes.

\section{Conclusions}

\section{Theorising the ethnic identity journey}

I am ... a Samoan . . . but not a Samoan

To my aiga in Samoa, I am a palagi.

I am . . . a New Zealander . . . but not a New Zealander.

To New Zealanders I am a "bloody coconut" at worst, a "Pacific Islander" at best,
I am ... to my Samoan parents ... their child.

The "I am" verse above arose out of the first author's doctoral research amongst a group of New Zealand-born Samoans of the Newton Pacific Islanders Congregational Church, the first Pacific ethnic church to be established in New Zealand. The verse depicts the core shared understanding of growing up as a New Zealand-born Samoan amongst the research participants (Anae, 1998, p. 159). Although based on New Zealand-born Samoan identity journeys, the "I am" verse can also be applied to New Zealand-born Pacific and other ethnic groups. The first two lines describe the simultaneous inter- and intra-ethnic identity confusion state they find themselves in-usually in their adolescent years-and the last line represents a reconciliation of inter- and intra-ethnic challenges to their self-perceived identities, which leads to a permanent secure identity.

Thus, ethnic identity is not to be explored as a static state but as a series of states or as a process changing over time and increasing maturity, that is, as a journey and a series of responses to challenges regarding one's self-identity (Anae, 1998). A secure ethnic identity is a political commitment to one's ethnic identity in the diaspora/transnational space; an ethnic identity in which coping mechanisms and strategies have been developed and which connects "roots" and "routes". It connects homeland/indigeneity with diaspora and transnationalism, with a positionality where one is comfortable and secure in one's own skin, despite inter- and intra-ethnic challenges from both the dominant settler group and their own ethnic group (Anae, 1997, 1998).

Courses/pedagogies such as Pacific 300 are integral because they provide students with ethnic enhancements through exegeses of their inter- and intra-ethnic relationships with others (Manuela \& Anae, 2017). They interrogate how individual success is understood, described and explained by Pacific students themselves. In the focus group interviews at the end of the course, students explained how the power of a secure ethnic identity provided them with a "sweet spot" - grounding, a balance, newfound confidence, self-reflexivity, and a new self-respect with which to view and pursue success, their studies, and their university and life experiences. Thus, the power of a secure ethnic identity will have flow-on effects at many levels.

In its ontology, epistemology and pedagogy, Pacific 300 demonstrates how to teu le va-a Samoan term meaning to value, nurture and act 
in the social and sacred spaces of relationships for optimal outcomes (Airini et al., 2010; Anae, 2010, 2016). This attention to relationality can help teachers positively re-vision their practice. Pacific 300 is about ethnic identity and the va, which necessitates a dialogical approach and also supports a relational positionality whereby both the student and the teacher become "edgewalkers" between Pacific and palagi concepts, Pacific Indigenous and palagi knowledges, Pacific and palagi communities, Pacific- and palagi-orientated pedagogies, and amongst themselves. Relatedness overlaps with dialogue, constituting relationships and flowing across relational spaces. While dialogue is to do with the way expression shapes relationships, relationships are more contexts for expression. In an intercultural educational setting, relational methodologies have the potential to facilitate interactions across groups of participants, for instance, teachers and students, catalysing
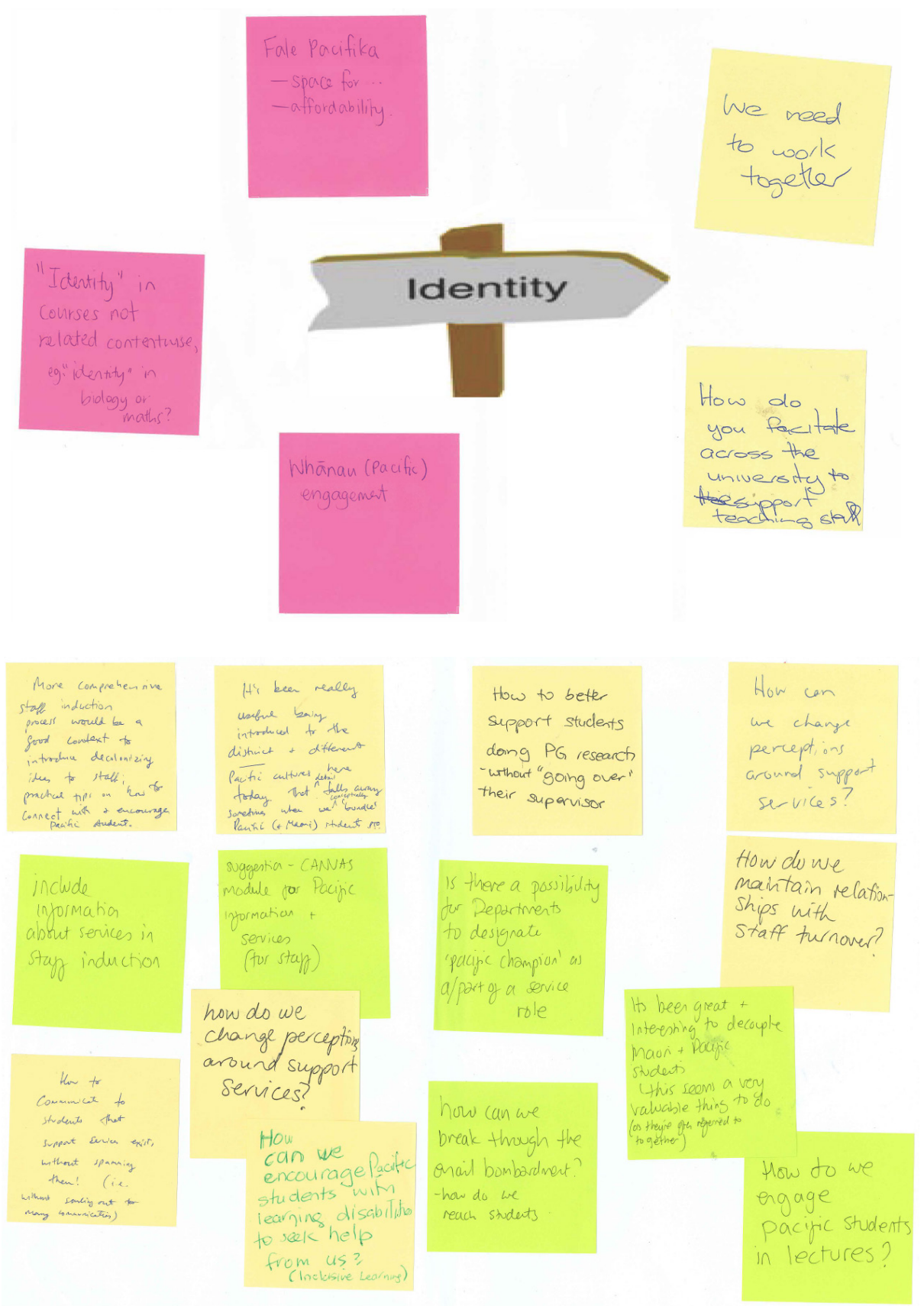

FIGURE 1 Post-it notes from fono participants gathered from faculty-based groups of departmental academic and professional staff 
relational intensity and enhancing understanding (Reynolds, 2016).

The learnings from this project can be understood through concepts such as va and a secured ethnic identity, disrupting existing thinking about Pacific students and what and who they represent. As a result, this research has the potential to assist a re-framing of theory and practice in the field, as well as providing a model of relational inquiry for further social justice research and praxis into intercultural fields such as Pacific education. These learnings also show how attention to, and indeed a focus on, va provides a relationality that can help teachers positively re-vision their practice.

The practice of teu le va has a strong tradition as a strategy for inquiry, meaning making, and dissemination of ideas in Pacific cultures. Researching and implementing strategies to enhance the engagement of Pacific students in their learning through ethnic identity journeys has the potential to improve participation, retention and success for Pacific students. Collaborative teaching and learning technologies provide an opportunity for both teachers and students to experience a range of diverse intercultural experiences and perspectives where culture counts.

\section{The fono}

The dissemination of our research findings occurred during a Pacific professional development fono for academic and professional staff members of the University of Auckland, which was held after the focus group sessions. Fono participants were provided with the research project findings as well as an opportunity to be immersed in Pacific-ness. The fono programme consisted of a welcomean ava ceremony by the Samoan students-and then the keynote speakers presented the research project data, followed by Pacific Island-themed workshops where fono participants were able to circulate amongst booths for a diverse range of Pacific nations. At these booths Pacific postgraduates shared specific Pacific Island-themed sociocultural aspects with them. This was followed by a talanoa-faculty/departmental groupings sharing reflections-and recommendations on ways forward. The programme ended with lunch and cultural performances.

We end our article with a visual form of feedback from staff who attended the dissemination fono, highlighting their needs, aspirations and desires for this vaka now and into the future (Figure 1). We believe the fono represented a great start to the liberating and healing process for both students and teachers of Pacific students.

\section{Faafetai/Acknowledgements}

With respect to the women of the various vaka moana who have lashed our canoes together in this time and place as we rest from our voyages to share rations, swap resources and share knowledge before untying and continuing our traversing of the blue continent, we give thanks. We acknowledge the the He Vaka Moana vision of Hinekura Smith and 'Ema Wolfgramm-Foliaki, who have steered us to this place and who have kept us watered and fed during this voyage. We also give thanks to our fellow voyagers, the Centre for Learning and Research in Higher Education (CLeaR) Fellows for 2018 who contributed to this special issue: Abigail McClutchie (Leadership Through Learning), Sonia Fonua (Embedding Indigenous Values Culture and Knowledge in Science), Marcia Leenen-Young (Pasifika Students Learning to Learn), Jacoba Matapo and Tim Staice (Decolonising Success in Higher Education and the Art of Wayfinding) and Ashlea Gillon (Growing the Fleet), as we create a star-path for our Pacific students and their teachers enabled by our CLeaR Fellowship projects in this special edition.

The authors are grateful to CLeaR at the University of Auckland for providing funding and support for the research project. We also thank the Maneaba team, the Pacific 3002018 course research participants, and Pacific Studies, Te Wānanga o Waipapa, University of Auckland.

\section{Glossary}

\begin{tabular}{|c|c|}
\hline afakasi & half-caste \\
\hline aiga & large extended family \\
\hline ava & $\begin{array}{l}\text { beverage made from the dried } \\
\text { roots of the plant Piper } \\
\text { methysticum and mixed with } \\
\text { water before it is strained } \\
\text { for drinking; used in ritual } \\
\text { ceremonies }\end{array}$ \\
\hline fono & meeting \\
\hline palagi & $\begin{array}{l}\text { lit. "sky-breaker", white man, } \\
\text { European, foreigner, Samoan } \\
\text { not born in Samoa }\end{array}$ \\
\hline $\begin{array}{l}\text { pikipiki hama } \\
\text { kae vaevae } \\
\text { manava }\end{array}$ & $\begin{array}{l}\text { pikipiki hama means to stick, } \\
\text { bind or link strongly to the } \\
\text { outrigger of a vaka moana; } \\
\text { vaevae means to give or share; } \\
\text { and manava- similar to } \\
\text { manawa in Māori-is a deeply } \\
\text { complex, core term in Pasifika } \\
\text { expression meaning the heart, } \\
\text { centre, womb or breath }\end{array}$ \\
\hline
\end{tabular}

talanoa sharing stories, creating dialogue in an inclusive receptive space 


$\begin{array}{ll}\begin{array}{l}\text { tamaitai } \\ \text { tautua }\end{array} & \begin{array}{l}\text { young, unmarried women } \\ \text { teu le va }\end{array} \\ & \begin{array}{l}\text { to value, nurture and to act in } \\ \text { the social and sacred/spiritual } \\ \text { spaces of relationships for } \\ \text { optimal outcomes } \\ \text { relationality; the sacred and } \\ \text { va }\end{array} \\ & \begin{array}{l}\text { secular/spiritual and social } \\ \text { animate and inanimate }\end{array} \\ \text { vaka moana } & \text { ocean-going canoe }\end{array}$

\section{Appendix 1: Demographic data}

See Figure A1.

\section{References}

Airini, Anae, M., \& Mila-Schaaf, K., with Coxon, E., Mara, D., \& Sanga, K. (2010). Teu le va: Relationships across research and policy: A collective approach to knowledge generation and policy development for action towards Pasifika education success. Ministry of Education.

Anae, M. (1997). Towards a NZ-born Samoan identity: Some reflections on "labels". Pacific Health
Dialog: Journal of Community Health and Clinical Medicine for the Pacific, 4(2), 128-137.

Anae, M. (1998). Fofoa-i-vao-'ese: The identity journeys of NZ-born Samoans [PhD thesis, University of Auckland]. ResearchSpace. http://hdl.handle. net/2292/66

Anae, M. (2010). Research for better Pacific schooling in New Zealand: Teu le va-a Samoan perspective. MAI Review, (1), 1-24.

Anae, M. (2016). Teu le va: A Samoan relational ethic. Knowledge Cultures, 4(3), 117-130.

Manuela, S., \& Anae, M. (2017). Pacific youth, acculturation and identity: The relationship between ethnic identity and well-being: New directions for research. Pacific Dynamics: Journal of Interdisciplinary Research, 1(1), 129-147.

Olsen, K., \& Shopes, L. (1991). Crossing boundaries: Burning bridges: Doing oral history with working class men and women. In S. B. Gluck \& D. Patai (Eds.), Women's words: The feminist practice of oral history (pp. 189-204). Routledge.

Reynolds, M. (2016). Relating to va: Re-viewing the concept of relationships in Pasifika education in Aotearoa New Zealand. Alternative, 12(2), 190-202. http://doi.org/c6k9

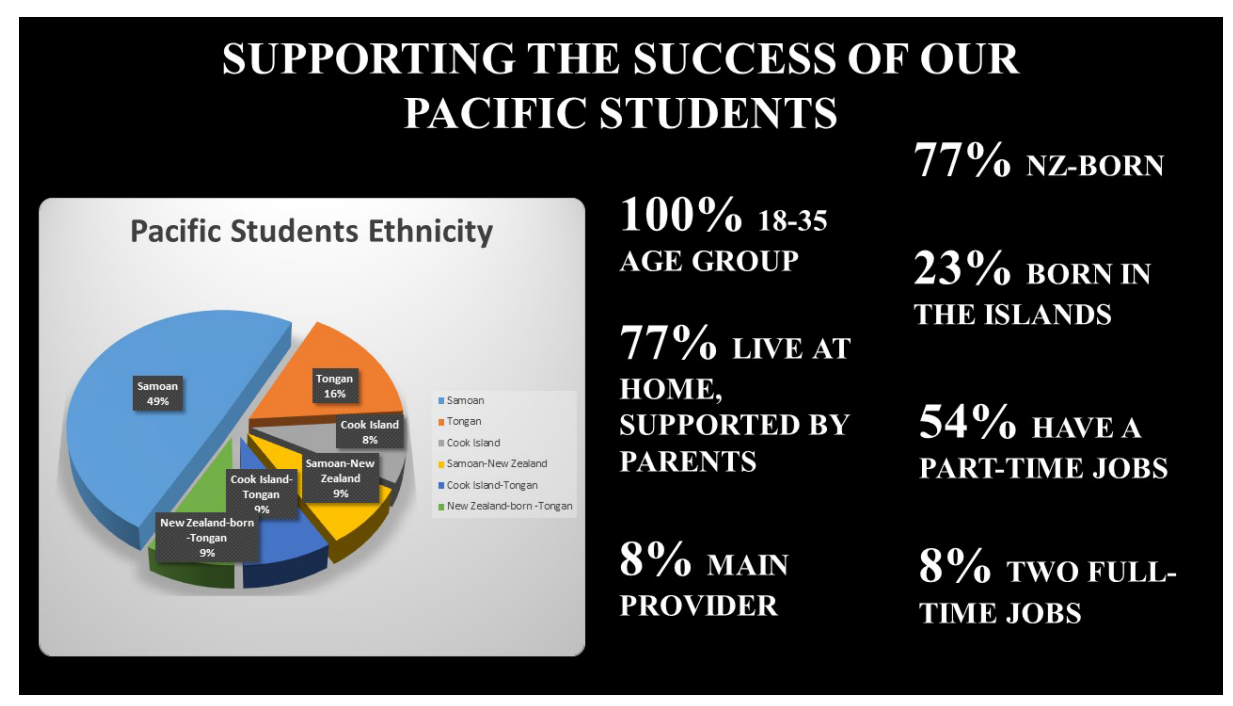

FIGURE A1 Demographic data collected from the students of Pacific 300: NZ-Born Pacific Identities who participated in the study 